\title{
Larvicidal, Ovicidal, and Repellent Activities of Marine Sponge Cliona celata (Grant) Extracts against Culex quinquefasciatus Say and Aedes aegypti L. (Diptera: Culicidae)
}

\author{
Appadurai Daniel Reegan, Arokia Valan Kinsalin, \\ Michael Gabriel Paulraj, and Savarimuthu Ignacimuthu \\ Entomology Research Institute, Loyola College, Chennai, Tamil Nadu 600 034, India \\ Correspondence should be addressed to Appadurai Daniel Reegan; danielreegan85@gmail.com
}

Received 15 September 2013; Accepted 3 October 2013

Academic Editors: M. V. Micieli and J. C. Navarro

Copyright (C) 2013 Appadurai Daniel Reegan et al. This is an open access article distributed under the Creative Commons Attribution License, which permits unrestricted use, distribution, and reproduction in any medium, provided the original work is properly cited.

\begin{abstract}
Solvent extracts of marine sponge Cliona celata (Grant) were screened for larvicidal, ovicidal, and repellent properties against the filarial vector Culex quinquefasciatus Say and dengue vector Aedes aegypti L. Larvicidal and ovicidal activities of hexane, ethyl acetate, and methanol extracts were tested in four different concentrations ranging as 62.5, 125, 250, and $500 \mathrm{ppm}$. Among the three solvent extracts of C. celata, methanol extract showed the highest larvicidal activity at $500 \mathrm{ppm}$ against both mosquito species. The $\mathrm{LC}_{50}$ and $\mathrm{LC}_{90}$ values of $C$. celata methanol extract were recorded as 95.63 and 242.16 ppm against C. quinquefasciatus larvae and 158.40 and 780.16 ppm against $A$. aegypti larvae, respectively. Ovicidal activity was high in methanol extract, in which $100 \%$ ovicidal activity was recorded in C. quinquefasciatus, and $72 \%$ ovicidal activity was recorded in A. aegypti at 500 ppm. The hexane extract was found to be the most effective protectant against the adult mosquitoes of both species. The mean protection time recorded in hexane extract was up to 273 and $165 \mathrm{~min}$ at $5 \mathrm{mg} / \mathrm{cm}^{2}$ dosage against $C$. quinquefasciatus and A. aegypti, respectively. Considering these bioactivities, $C$. celata could be used to obtain some novel pesticidal molecules.
\end{abstract}

\section{Introduction}

Mosquitoes are the major arthropod vectors and the most dangerous human health pests. The war against mosquitoes using chemical pesticides has failed due to the resistance developed by mosquitoes $[1,2]$. Chemical control of mosquitoes is also causing many unwanted effects on human health and nontarget animals. By understanding these side effects of chemicals, people are now showing interest towards biopesticides and botanical formulations, which are considered as eco-friendly. Nature is providing numerous bioactive products against vector mosquitoes in the form of plant products, marine products, microbial products, and other biological derivatives. Culex quinquefasciatus is a major vector of Wuchereria species causing lymphatic filariasis; it is widely distributed in tropical regions with around 120 million people getting infected and 44 million people under clinical manifestation [3]. India alone contributes around $40 \%$ of global filariasis burden, and the estimated annual economic loss is about 720 crore Indian rupees [4]. The mosquito Aedes aegypti is more widely distributed in tropical and subtropical regions of the world. It is a major vector of arboviruses causing chikungunya and dengue fever. Natural insecticides are generally pest specific, biodegradable, usually nonallergic to human as well as nontarget organisms [5], and they may possess novel compounds with a wide range of activities [6,7]. In recent years, plant products and phytochemicals have been studied for the control of mosquitoes [8-12]. Likewise, some investigators have reported that the secondary metabolites of marine sponges possessed insecticidal activities [13-16].

Sponges (Phylum: Porifera) are the oldest metazoan organisms and have been recognized as a rich source of biologically active compounds that are of potential interest to mankind $[17,18]$ and are good alternatives for synthetic pesticides [19]. They are a potential source of novel antimicrobial agents [20]. Till date, nearly 8000 species of sponges 
have been described throughout the world, and 108 species of sponges have been identified in Gulf of Mannar, India [21]. Till date, practically very few species of sponges have been studied for their mosquito larvicidal activity [22-25]. However, studies on mosquitocidal properties of marine sponges from Indian waters are limited, and the larvicidal, ovicidal and repellent efficacy of the marine sponge Cliona celata (Porifera: Hadromerida: Clionidae) has not been studied previously. Hence, the present study was undertaken to screen the crude extracts of marine sponge $C$. celata from the Gulf of Mannar for their larvicidal, ovicidal, and repellent activities against two vector mosquitoes $C$. quinquefasciatus and $A$. aegypti.

\section{Materials and Methods}

2.1. Collection of Sponges. Marine sponge C. celata was collected from the Gulf of Mannar (between $8^{\circ} 47^{\prime}$ to $9^{\circ} 05^{\prime} \mathrm{N}$ Latitude and $78^{\circ} 12^{\prime}$ to $79^{\circ} 07^{\prime} \mathrm{E}$ Longitude, India) at depths varying from 15 to 25 feet by scubadiving. Sponges were gently removed from the substratum and transferred to laboratory within $48 \mathrm{~h}$; then, the specimen was identified and deposited (deposition number: MBRC/ZSI-S.225) in National Zoological Collection of Marine Bio Resource Centre, Zoological Survey of India $\left(13^{\circ} 04^{\prime} \mathrm{N}\right.$ Latitude and $80^{\circ} 17^{\prime} \mathrm{E}$ Longitude, India).

2.2. Preparation of Crude Extracts. The Marine sponge $C$. celata was thoroughly washed with distilled water to remove the sand particles and cut into small pieces before shade drying for $48 \mathrm{~h}$. Then the sponges were homogenized and extracted sequentially with hexane, ethyl acetate, and methanol. Initially the powder of the C. celata $(500 \mathrm{~g})$ was soaked in 1 litre hexane for $72 \mathrm{~h}$ and filtered through filter paper. The residue was dried and then extracted sequentially with ethyl acetate and methanol solvents after $72 \mathrm{~h}$ of soaking in each solvent separately. The extracts were condensed separately under reduced pressure by using vacuum evaporator, and the solvent free crude extracts were collected in glass vials and stored in $4^{\circ} \mathrm{C}$ until use. Stock solutions $(10 \%$ in acetone) of all the three solvent extracts were prepared and then subjected to bioassay screening.

2.3. Test Insect. Eggs, larvae, and adults of C. quinquefasciatus and $A$. aegypti were obtained from the stock culture maintained at Entomology Research Institute, which were free of exposure to pathogens, insecticides, or repellents. Laboratory rearing was done at a temperature of $27 \pm 2^{\circ} \mathrm{C}, 75-85 \%$ relative humidity, and a photoperiod of $11 \pm 0.5 \mathrm{~h}$.

2.4. Larvicidal Bioassay. Larvicidal activity was evaluated by following the methods of WHO [26] with slight modifications. Twenty numbers of early fourth instar larvae of C. quinquefasciatus and $A$. aegypti were introduced into the test containers. The extracts taken in four concentrations were 500, 250, 125, and $62.5 \mathrm{ppm}$. Normal control and solvent control (Acetone in water) were maintained separately. Mortality rate were registered after $24 \mathrm{~h}$ exposure period. The moribund and dead larvae were collected, and larval mortality was calculated for each concentration. The bioassays were performed at a room temperature of $27 \pm$ $1^{\circ} \mathrm{C}$ with five replicates for each concentration. Mortality was converted into percent mortality (a), and corrected mortality was calculated using Abbot's formula (b) [27].

(a) Percentage of mortality is as follows:

$$
\frac{\text { no. of dead larvae }}{\text { no. of larvae introduced }} \times 100 \text {. }
$$

(b) Corrected percentage of mortality is as follows:

$$
\frac{1-n \text { in } \mathrm{T} \text { after treatment }}{N \text { in } \mathrm{C} \text { after treatment }} \times 100,
$$

where $n$ is the number of larvae, T is the number of larvae survived in treated, and $\mathrm{C}$ is the number of larvae survived in control.

The corrected percentage mortality value of each concentration was considered to estimate $\mathrm{LC}_{50}$ and $\mathrm{LC}_{90}$ values using SPSS Probit analysis statistical pack, version 11.5.

2.5. Ovicidal Bioassay. Ovicidal activity was evaluated by following the method of Elango et al. [28] with slight modification. Twenty five freshly laid eggs of $C$. quinquefasciatus and A. aegypti were treated separately with the C. celata extracts at $62.5,125,250$, and 500 ppm concentrations. Normal control was kept separately. Acetone in water was served as solvent control. Each treatment was replicated five times. The ovicidal activity was assessed up to $120 \mathrm{~h}$ posttreatment and thereafter control; treated eggs were observed under the microscope and photographed using stereo zooming microscope (Wild M7S TYP 308700, Switzerland). The nonhatched eggs with unopened opercula were counted in each treatment, and the percent mortality was calculated using the following formula and analysed in Graph Pad Prism version 3.0 for Windows, Graph Pad Software, San Diego, CA, USA:

$$
\% \text { of egg mortality }=\frac{\text { No. of unhatched eggs }}{\text { Total No. of eggs }} \times 100 \text {. }
$$

2.6. Repellent Bioassay. For repellent experiment, 3 to 6 days old, hundred laboratory reared blood-starved adult female mosquitoes were introduced into separate laboratory cages $(45 \times 45 \times 40 \mathrm{~cm})$. C. quinquefasciatus was tested during the night time, while $A$. aegypti was tested during the day time. Before each test, the forearms of a human subject were washed with unscented neutral soap, thoroughly rinsed, and allowed to dry before the application of the extract at $5,2.5$, and $1 \mathrm{mg} / \mathrm{cm}^{2}$ concentrations. The C. celata extracts being tested were applied on the right upper forearm and remaining regions were covered with gloves. The arm was left undisturbed. The left arm served as control. N-N Diethyl benzamide $(12 \%, \mathrm{w} / \mathrm{w})$ was used as negative control. The mosquito bites were observed for three full minutes of every fifteen minutes. Protection time was recorded as the time that elapsed between extract application and the observation period immediately preceding that in which a confirmed bite 
TABLE 1: Lethal concentration (in ppm) of C. celata extracts against the larvae of $C$.

\begin{tabular}{|c|c|c|c|c|c|c|c|c|c|c|}
\hline \multirow{2}{*}{ Mosquito species } & \multirow{2}{*}{ Treatment } & \multirow{2}{*}{$\begin{array}{c}\mathrm{LC}_{50} \\
(\mathrm{ppm})\end{array}$} & \multicolumn{2}{|c|}{ 95\% confidence limit } & \multirow{2}{*}{$\begin{array}{c}\mathrm{LC}_{90} \\
(\mathrm{ppm})\end{array}$} & \multicolumn{2}{|c|}{ 95\% confidence limit } & \multirow{2}{*}{ Slope \pm SE } & \multirow{2}{*}{ Intercept \pm SE } & \multirow{2}{*}{$\chi^{2}$} \\
\hline & & & LL & UL & & LL & UL & & & \\
\hline \multirow{3}{*}{$\begin{array}{l}\text { Culex } \\
\text { quinquefasciatus }\end{array}$} & Hexane & 268.28 & 165.88 & 441.84 & 1008.42 & 559.85 & 6552.24 & $2.2 \pm 0.6$ & $-0.4 \pm 1.5$ & $0.06^{*}$ \\
\hline & Ethyl acetate & 218.71 & 129.78 & 359.38 & 970.53 & 518.88 & 6501.77 & $1.9 \pm 0.5$ & $0.3 \pm 1.2$ & $0.3^{*}$ \\
\hline & Methanol & 95.63 & 61.22 & 127.45 & 242.16 & 176.09 & 460.04 & $3.1 \pm 0.7$ & $-1.2 \pm 1.5$ & $0.3^{*}$ \\
\hline \multirow{3}{*}{ Aedes aegypti } & Hexane & 364.71 & 239.50 & 585.41 & 897.53 & 567.82 & 8000.22 & $3.2 \pm 1.1$ & $-3.3 \pm 2.9$ & $0.05^{*}$ \\
\hline & Ethyl acetate & 285.65 & 176.91 & 475.96 & 1033.36 & 575.13 & 7376.91 & $2.2 \pm 0.6$ & $-0.6 \pm 1.6$ & $0.2^{*}$ \\
\hline & Methanol & 158.40 & 84.60 & 249.72 & 780.16 & 423.58 & 4793.81 & $1.8 \pm 0.5$ & $0.9 \pm 1.1$ & $0.09^{*}$ \\
\hline
\end{tabular}

Culex quinquefasciatus and A. aegypti.

$\mathrm{LC}_{50}$ lethal concentration that kills $50 \%$ of the exposed larvae, $\mathrm{LC}_{90}$ lethal concentration that kills $90 \%$ of the exposed larvae, LL lower limit (95\% confidence limit), and UL upper limit (95\% confidence limit).

${ }^{*} P \leq 0.05$, level of significance of chi-square values.
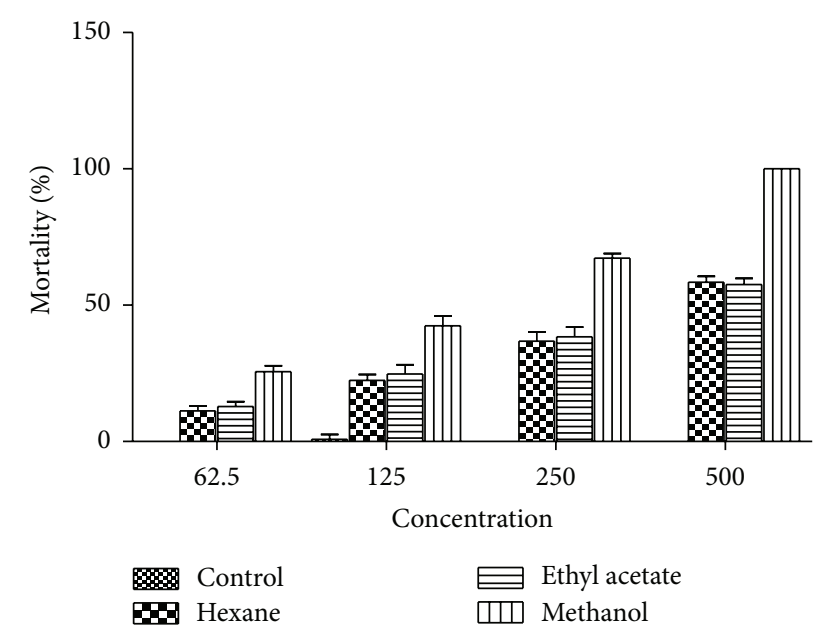

Figure 1: Percent ovicidal activity of marine sponge C. celata extracts against the eggs of $C$. quinquefasciatus.

was obtained. The experiments were replicated five times in separate cages, and in each replicate different volunteer was used to nullify any effect of skin differences on repellence. The protection time of each extract was calculated using previously established methods [29, 30].

2.7. Statistical Analysis. The results were presented as mean \pm SD. Statistical analyses of all the data obtained in larvicidal activity were evaluated using Probit analysis (SPSS Program; Version 11.5). The differences were considered as significant at $P \leq 0.05$.

\section{Results}

3.1. Larvicidal Activity and Lethal Doses. All the three extracts of the sponge $C$. celata showed larvicidal activity. The larvicidal activity varied between the solvent extracts and the mosquito species. Table 1 shows the results on effective lethal concentration $\left(\mathrm{LC}_{50}\right.$ and $\mathrm{LC}_{90}$ ) values of hexane, ethyl acetate, and methanol extracts of $C$. celata after $24 \mathrm{~h}$ treatment period. It was clear from the results that the methanol extract recorded the maximum larvicidal activity in both C. quinquefasciatus and $A$. aegypti. The $\mathrm{LC}_{50}$ and $\mathrm{LC}_{90}$
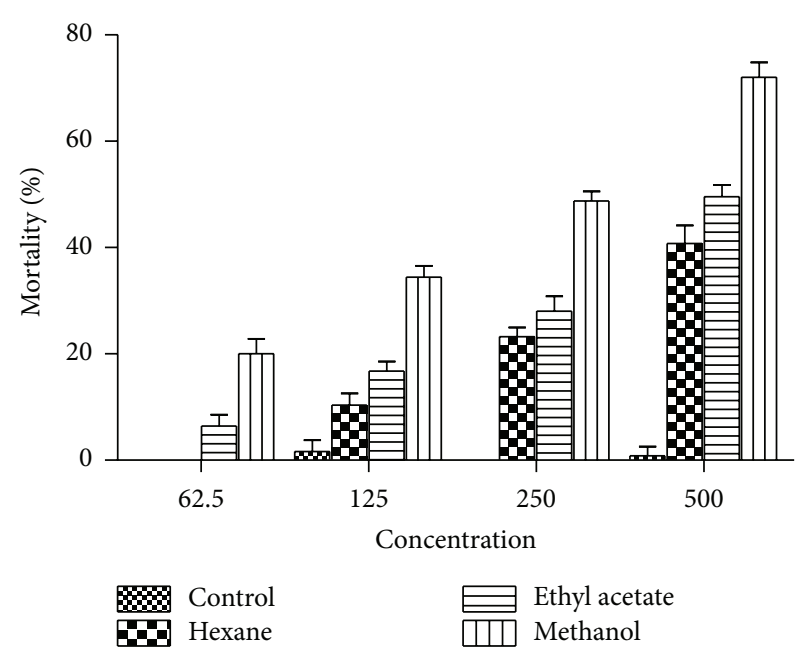

Figure 2: Percent ovicidal activity of marine sponge $C$. celata extracts against the eggs of $A$. aegypti.

values of methanol extract recorded in C. quinquefasciatus were 95.63 and $242.16 \mathrm{ppm}$, respectively (Table 1). A. aegypti was less susceptible than C. quinquefasciatus, and the $\mathrm{LC}_{50}$ and $\mathrm{LC}_{90}$ values of methanol extract for $A$. aegypti were 158.40 and $780.16 \mathrm{ppm}$, respectively. Significant chi-square values were recorded in all the extracts (Table 1 ). In normal control and solvent control, all the larvae were active and exhibited normal movement. But in the treated larvae, restless movement was observed. After $1 \mathrm{~h}$, tremor and convulsion were observed in all the treated larvae and dead larvae settled down as reported earlier [31].

3.2. Ovicidal Activity. The ovicidal activities of $C$. celata extracts on $C$. quinquefasciatus and $A$. aegypti eggs are given in Figures 1 and 2. Methanol extract was found to be highly lethal to the eggs of both species. In C. quinquefasciatus, methanol extract presented $100 \%$ ovicidal activity at $500 \mathrm{ppm}$ concentration after $120 \mathrm{~h}$ posttreatment period. The lowest concentration $(62.5 \mathrm{ppm})$ of methanol extract caused $25.6 \%$ egg mortality in C. quinquefasciatus. A. aegypti eggs were found to be more tolerant to all the three extracts of $C$. celata 
TABLE 2: Complete protection time of three solvent extracts of $C$. celata against C. quinquefasciatus.

\begin{tabular}{lccc}
\hline Extract & $\begin{array}{c}\text { Concentration } \\
\mathrm{mg} / \mathrm{cm}^{2}\end{array}$ & $\begin{array}{c}\text { Complete protection time (min) } \\
\text { Control }\end{array}$ & $\begin{array}{c}\text { Treated } \\
\text { Hexane }\end{array}$ \\
\hline & 2.0 & $1.4 \pm 0.54$ & $105 \pm 3.16$ \\
& 5.0 & $2.2 \pm 0.83$ & $150 \pm 2.91$ \\
Ethyl acetate & 1.0 & $1.6 \pm 0.54$ & $44 \pm 2.73$ \\
& 2.5 & $1.1 \pm 0.19$ & $99 \pm 3.16$ \\
& 5.0 & $1.4 \pm 0.54$ & $178 \pm 1.58$ \\
Methanol & 1.0 & $1.2 \pm 0.44$ & $44 \pm 2.44$ \\
& 2.5 & $1.6 \pm 1.34$ & $76 \pm 2.73$ \\
\hline \multirow{2}{*}{ N-N Diethyl } & 5.0 & $1.8 \pm 0.44$ & $120 \pm 2.73$ \\
benzamide 12\% & 1.0 & $2.4 \pm 0.89$ & $110 \pm 1.0$ \\
& 2.5 & $1.8 \pm 0.83$ & $194 \pm 1.58$ \\
& 5.0 & $2.0 \pm 0.70$ & $323 \pm 2.0$ \\
\hline
\end{tabular}

at all concentrations. At the highest concentration (500 ppm) of methanol extract, $72 \%$ ovicidal activity was noticed in A. aegypti after $120 \mathrm{~h}$ posttreatment period. In both species, the ovicidal effect of all the three extracts was directly proportional to the concentration. In methanol extract treated C. quinquefasciatus eggs, most of them did not hatch and some were hatched in an abnormal way at $500 \mathrm{ppm}$ and the larvae died before completion of eclosion (Figure 3(b)). The methanol extract-treated eggs of A. aegypti were shrunken and most did not hatch at $500 \mathrm{ppm}$ concentration (Figure 4(b)). In normal control and solvent control, hatchability of eggs of both species was normal (Figures 3(a) and 4(a)).

3.3. Repellent Activity. The complete protection times for all the three extracts of $C$. celata against both the species of mosquitoes were recorded by standard skin repellence experiments, and the results are given in Tables 2 and 3. The repellence was directly proportional to the dose and protection time ( $\mathrm{min}$ ) for each extract showed variations between two species. In general hexane extract gave maximum protection time against both mosquito species compared to ethyl acetate and methanol extracts. Furthermore, it was noted that all the three extracts were found to be more effective against $C$. quinquefasciatus than $A$. aegypti mosquitoes. Hexane extract gave a maximum protection time of $273 \mathrm{~min}$ against $C$. quinquefasciatus at $5 \mathrm{mg} / \mathrm{cm}^{2}$ dosage (Table 2). The same treatment recorded the highest protection time of $165 \mathrm{~min}$ against $A$. aegypti at $5 \mathrm{mg} / \mathrm{cm}^{2}$ dosage (Table 3). These results were comparable with negative control (N-N Diethyl benzamide $12 \%$, w/w), which showed maximum of 323 and $182 \mathrm{~min}$ protection at $5 \mathrm{mg} / \mathrm{cm}^{2}$ dosage against $C$. quinquefasciatus and A. aegypti mosquitoes, respectively.

\section{Discussion}

Searching for eco-friendly pesticide molecules among natural sources has become an important research in these days,
TABLE 3: Complete protection time of three solvent extracts of $C$. celata against $A$. aegypti.

\begin{tabular}{lccc}
\hline Extract & $\begin{array}{r}\text { Concentration } \\
\mathrm{mg} / \mathrm{cm}^{2}\end{array}$ & $\begin{array}{c}\text { Complete protection time (min) } \\
\text { Control }\end{array}$ & $\begin{array}{c}\text { Treated } \\
\text { Hexane }\end{array}$ \\
\hline & 2.0 & $0.33 \pm 1.11$ & $44 \pm 1.58$ \\
& 5.0 & $0.30 \pm 0.08$ & $87 \pm 2.54$ \\
Ethyl acetate & 1.0 & $0.51 \pm 0.30$ & $28 \pm 1.58$ \\
& 2.5 & $1.16 \pm 0.11$ & $64 \pm 3.16$ \\
& 5.0 & $0.35 \pm 0.10$ & $118 \pm 1.87$ \\
Methanol & 1.0 & $1.2 \pm 0.44$ & $25 \pm 2.12$ \\
& 2.5 & $0.51 \pm 0.05$ & $51 \pm 1.58$ \\
& 5.0 & $0.40 \pm 0.10$ & $75 \pm 2.91$ \\
N-N Diethyl & 1.0 & $1.2 \pm 0.70$ & $55 \pm 1.0$ \\
benzamide 12\% & 2.5 & $1.4 \pm 0.54$ & $95 \pm 1.41$ \\
& 5.0 & $1.2 \pm 0.44$ & $182 \pm 0.70$ \\
\hline
\end{tabular}

and it is promoted for mosquito control than chemical insecticides [32]. Nature is providing innumerable bioactive molecules for the well-being of mankind. Plant kingdom and marine organisms provide majority of the beneficial biomolecules or products that are used by people in their daily life. Marine sponges are known to produce toxins and other compounds to repel and deter predators $[33,34]$. These compounds of marine sponges are reported to be of the bioactive compounds which can be used in the treatment of many diseases [35-39].

In recent years, researchers are concentrating on marine organisms to study their biological activities; especially, marine sponges (Porifera) have attracted significant attention from various scientific disciplines [40]. The literature also indicates that the marine products possess maximum percentage of bioactive substances with novel biological properties than the molecules originating from terrestrial origin [24, 41]. Recently, marine sponge extracts and their compounds have been screened for antimicrobial $[42,43]$, antiplasmodicidal [44], antifilarial [45, 46], and antihelminthic activity [47]. Marine sponge extracts have also been screened against agricultural pests. Edrada et al. [48] have reported an insecticidal and growth regulating compound from the philippine marine sponge Xestospongia ashmorica against Spodoptera littoralis, an important polyphagous pest. Supriyono et al. [49] have reported that two guanidine alkaloids, namely, hymenialdisine and debromohymenialdisine from the tropical marine sponge Axinella carteri exhibited insecticidal activity with $L_{50}$ value of 88 and $125 \mathrm{ppm}$, respectively, against the neonate larvae of $S$. littoralis in feeding bioassay experiments.

In this regard, very few researchers have studied the mosquitocidal potential of marine sponge extracts. Venkateswara Rao et al. [23] have screened the methanoldichloromethane $(1: 1)$ extracts of 18 different sponges collected from Palk bay and Gulf of Mannar waters against A. aegypti and houseflies (Musca domestica). They found that Psammaplysilla purpurea $\left(\mathrm{LC}_{50}=25.9 \mathrm{ppm}\right)$ and Haliclona 


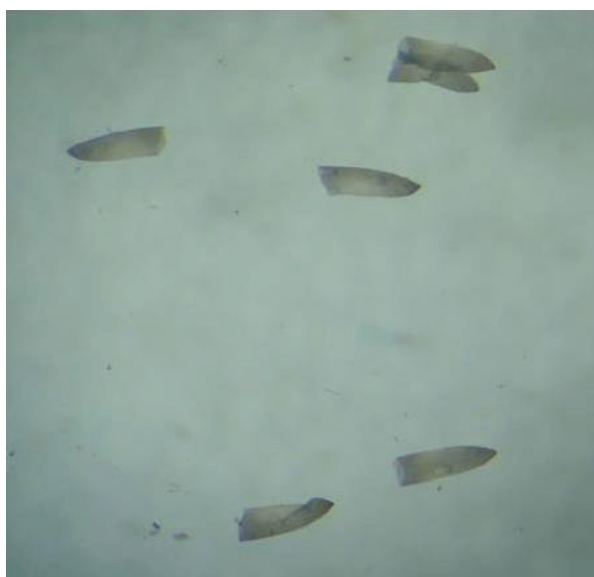

(a)

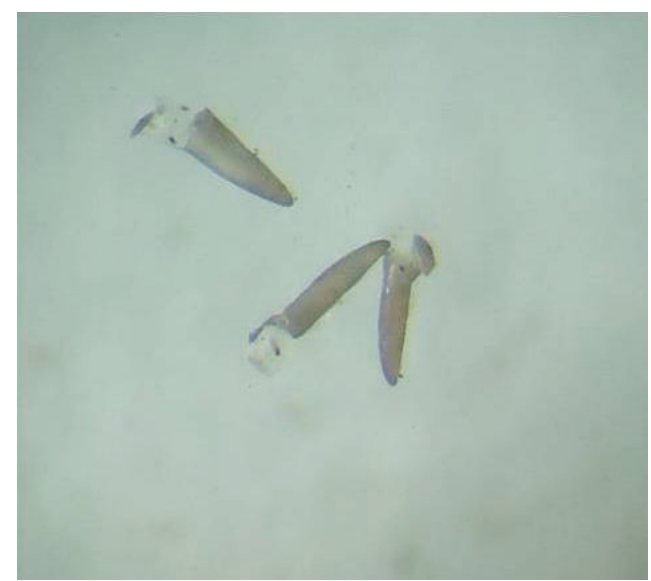

(b)

Figure 3: Hatched eggs of C. quinquefasciatus in control (a). The larvae of C. quinquefasciatus died in the egg case before completion of eclosion in methanol extract treated C. celata after $120 \mathrm{~h}$ posttreatment (b).

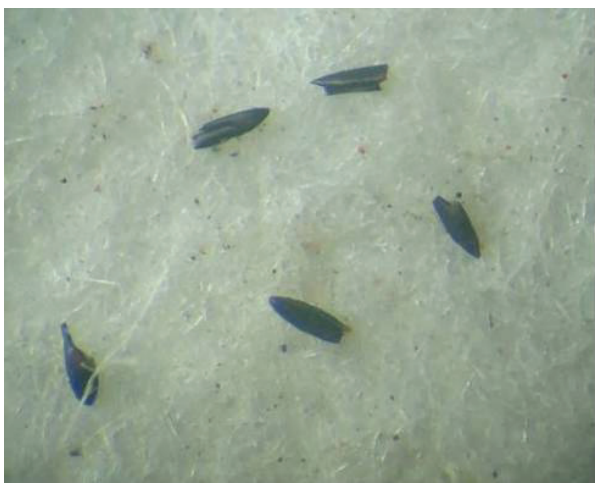

(a)

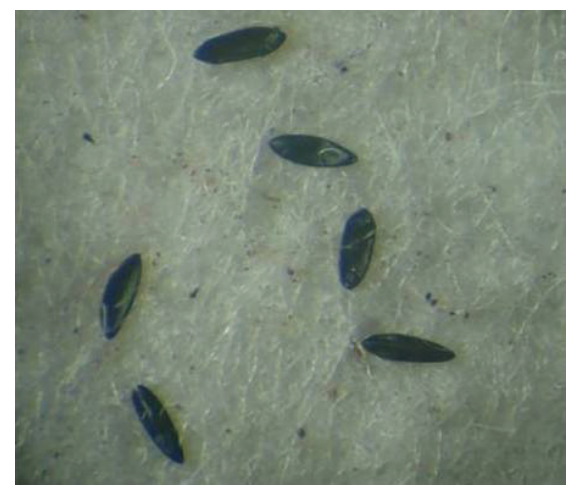

(b)

FIgURE 4: Hatched eggs of A. aegypti in control (a). Dead and shrunken eggs of $A$. aegypti in methanol extract treated C. celata after $120 \mathrm{~h}$ posttreatment (b).

cribricutis $\left(\mathrm{LC}_{50}=31.46 \mathrm{ppm}\right)$ were more effective against A. aegypti mosquito larvae. In our study, we observed that the methanol extract of $C$. celata was the most effective in larvicide, and the $\mathrm{LC}_{50}$ of methanol extract against $C$. quinquefasciatus was found to be higher (95.63 ppm) than A. aegypti $(158.40 \mathrm{ppm})$ values. An interesting finding in this study was that the low polar solvent extract; that is, hexane extract showed repellent activity and the high polar solvent (methanol) extract showed larvicidal and ovicidal activities. This result was comparable with the earlier report of Sonia and Lipton [25] who have screened the methanol extracts of five marine sponges, namely, Acanthella elongata, Echinodictyum gorgonoides, Axinella donnani, Callyspongia subarmigera, and Callyspongia diffusa for larvicidal activity against Culex sp. They found that Acanthella elongata extract was the most effective with the $\mathrm{LC}_{50}$ value of $0.066 \mathrm{mg} / \mathrm{mL}$ than other extracts.

In the present study, all the three solvent extract treatments were not equally effective against $C$. quinquefasciatus and $A$. aegypti larvae, eggs, and adults. C. quinquefasciatus life stages were found to be more susceptible to the treatments than A. aegypti. A similar result was reported by Martínez et al. [22]; they have screened the ethanol extracts of five marine sponges, namely, Amphimedon compressa, Topsentia ophiraphidites, Svenzea zeai, Ircinia campana, and Agelas sventres against fourth instar larvae of $A$. aegypti and $C$. quinquefasciatus. They found that Ircinia campana extract was the most effective against the larvae of two mosquitoes and the activity was higher in $A$. aegypti than C. quinquefasciatus.

Earlier, Rey et al. [50] and David et al. [51] proved that the plant extracts primarily affect the midgut epithelium, and this is based on the concentration, duration of the treatment, and mosquito species used. Further, Daniel Reegan et al. [52] proved that the orange peel extract primarily damages the midgut epithelial columnar cells, gastric caeca (GC), and brush border cells (BB) in the treated larvae of $A$. stephensi. Acetylcholinesterase (AChE) is the molecular target for mosquito repellents [53]. Possibly, these extracts of marine sponge $C$. celata may have impact on midgut cells of the treated larvae and on AChE. 


\section{Conclusion}

In Conclusion, the present study reports for the first time repellent, larvicidal, and ovicidal activities of marine sponge C. celata against $C$. quinquefasciatus and $A$. aegypti. The screening results suggest that the hexane and methanol extracts of C. celata are promising in mosquito control and repellent. This is an eco-friendly alternative to chemical insecticide which is promising in mosquito control.

\section{Conflict of Interests}

The authors declare that they have no conflict of interests.

\section{Authors' Contribution}

Appadurai Daniel Reegan and Arokia Valan Kinsalin contributed equally to this paper.

\section{Acknowledgments}

The authors are thankful to Entomology Research Institute, Loyola College for financial assistance. The authors are grateful to Dr. G. Sivaleela, Scientist, MBRC, Zoological Survey of India, for the cooperation and contribution in identifying the marine sponge.

\section{References}

[1] WHO, Lymphatic Filariasis: The Disease and Its Control, Technical Report Series, WHO, Geneva, Switzerland, 1992.

[2] H. Liu, Q. Xu, L. Zhang, and N. Liu, "Chlorpyrifos resistance in mosquito Culex quinquefasciatus," Journal of Medical Entomology, vol. 42, no. 5, pp. 815-820, 2005.

[3] L. Bernhard, P. Bernhard, and P. Magnussen, "Management of patients with lymphoedema caused by filariasis in north-eastern Tanzania," Physiotherapy, vol. 89, no. 12, pp. 743-749, 2003.

[4] P. J. Hotez, J. H. F. Remme, P. Buss, G. Alleyne, C. Morel, and J. G. Breman, "Combating tropical infectious diseases: Report of the Disease Control Priorities in Developing Countries Project," Clinical Infectious Diseases, vol. 38, no. 6, pp. 871-878, 2004.

[5] W. S. Bowers, "Biorational approaches for insect control," Korean Journal of Applied Entomology, vol. 31, pp. 289-303, 1992.

[6] H. Schmutterer, The Neem Tree Azadirachta Indica and Other Meliaceous Plants, VCH, Weinneim, Germany, 1995.

[7] A. Ghosh, N. Chowdhury, and G. Chandra, "Laboratory evaluation of a phytosteroid compound of mature leaves of Day Jasmine (Solanaceae: Solanales) against larvae of Culex quinquefasciatus (Diptera: Culicidae) and nontarget organisms," Parasitology Research, vol. 103, no. 2, pp. 271-277, 2008.

[8] H. Mehlhorn, G. Schmahl, and J. Schmidt, "Extract of the seeds of the plant Vitex agnus castus proven to be highly efficacious as a repellent against ticks, fleas, mosquitoes and biting flies," Parasitology Research, vol. 95, no. 5, pp. 363-365, 2005.

[9] A. Amer and H. Mehlhorn, "Repellency effect of forty-one essential oils against Aedes, Anopheles, and Culex mosquitoes," Parasitology Research, vol. 99, no. 4, pp. 478-490, 2006.
[10] R. M. Gleiser and J. A. Zygadlo, "Insecticidal properties of essential oils from Lippia turbinata and Lippia polystachya (Verbenaceae) against Culex quinquefasciatus (Diptera: Culicidae)," Parasitology Research, vol. 101, no. 5, pp. 1349-1354, 2007.

[11] M. Govindarajan, A. Jebanesan, and T. Pushpanathan, "Larvicidal and ovicidal activity of Cassia fistula Linn. leaf extract against filarial and malarial vector mosquitoes," Parasitology Research, vol. 102, no. 2, pp. 289-292, 2008.

[12] C. Muthu, A. Daniel Reegan, S. Kingsley, and S. Ignacimuthu, "Larvicidal activity of pectolinaringenin from Clerodendrum phlomidis L. against Culex quinquefasciatus Say and Aedes aegypti L. (Diptera: Culicidae)," Parasitology Research, vol. 111, no. 3, pp. 1059-1065, 2012.

[13] B. Weiss, R. Ebel, M. Elbrächter, M. Kirchner, and P. Proksch, "Defense metabolites from the marine sponge Verongia aerophoba," Biochemical Systematics and Ecology, vol. 24, no. 1, pp. 1-12, 1996.

[14] M. Balbin-Oliveros, R. A. Edrada, P. Proksch, V. Wray, L. Witte, and R. W. M. Van Soest, "A new meroditerpenoid dimer from an undescribed Philippine marine sponge of the genus Strongylophora," Journal of Natural Products, vol. 61, no. 7, pp. 948-952, 1998.

[15] A. Okada, K. Watanabe, K. Umeda, and M. Miyakado, "Calyculin $\mathrm{E}$ and $\mathrm{F}$, novel insecticidal metabolites from the marine sponge, Discoderma sp," Agricultural and Biological Chemistry, vol. 55, pp. 2765-2771, 2006.

[16] N. Y. Funda, "Biological activities of the marine sponge auxinella," Journal of Faculty of Pharmacy, vol. 14, pp. 47-60, 2007.

[17] D. J. Faulkner, "Marine pharmacology," Antonie van Leeuwenhoek, vol. 77, no. 2, pp. 135-145, 2000.

[18] J. W. Blunt, B. R. Copp, M. H. G. Munro, P. T. Northcote, and M. R. Prinsep, "Marine natural products," Natural Product Reports, vol. 22, no. 1, pp. 15-61, 2005.

[19] M. O. Fatope, H. Ibrahim, and Y. Takeda, "Screening of higher plants reputed as pesticides using the brine shrimp lethality assay," International Journal of Pharmacognosy, vol. 31, no. 4, pp. 250-254, 1993.

[20] J. Selvin and A. P. Lipton, "Biopotentials of secondary metabolites isolated from marine sponges," Hydrobiologia, vol. 513, pp. 231-238, 2004.

[21] V. P. Limna Mol, T. V. Raveendran, K. R. Abhilash, and P. S. Parameswaran, "Inhibitory effect of Indian sponge extracts on bacterial strains and larval settlement of the barnacle, Balanus amphitrite," International Biodeterioration and Biodegradation, vol. 64, no. 6, pp. 506-510, 2010.

[22] A. M. Martínez, E. J. Galeano, J. Cadavid, Y. R. Miranda, J. L. Llano, and Y. K. M. Montalvo, "Insecticide action of ethanol extracts of sponges from Urabá Gulf on Aedes aegypti and Culex quinquefasciatus larvae. Vitae," Revista de la Facultad de Química Farmacéutica, vol. 14, no. 2, pp. 90-94, 2007.

[23] J. Venkateswara Rao, P. K. Usman, and J. Bharat Kumar, "Larvicidal and insecticidal properties of some marine sponges collected in Palk Bay and Gulf of Mannar waters," African Journal of Biotechnology, vol. 7, no. 2, pp. 109-113, 2008.

[24] S. Sujatha and B. Joseph, "Effect of few marine sponges and its biological activity against Aedes aegypti Linn. Musca domestica (Linnaeus, 1758) (Diptera: Culicidae)," Journal of Fisheries and Aquatic Science, vol. 6, no. 2, pp. 170-177, 2011.

[25] A. S. G. Sonia and A. P. Lipton, "Mosquito Larvicidal activity of marine sponge metabolites," Global Journal of Pharmacology, vol. 6, no. 1, pp. 1-3, 2012. 
[26] WHO, Guidelines for Laboratory and Field Testing of Mosquito Larvicides, WHO/CDS/WHOPES/GCDPP/13, WHO, Geneva, Switzerland, 2005.

[27] W. S. Abbott, "A method of computing the effectiveness of an insecticide," Journal of Economic Entomology, vol. 18, pp. 265267, 1925

[28] G. Elango, A. Bagavan, C. Kamaraj, A. Abduz Zahir, and A. Abdul Rahuman, "Oviposition-deterrent, ovicidal, and repellent activities of indigenous plant extracts against Anopheles subpictus Grassi (Diptera: Culicidae)," Parasitology Research, vol. 105, no. 6, pp. 1567-1576, 2009.

[29] M. S. Fradin and J. F. Day, "Comparative efficacy of insect repellents against mosquito bites," The New England Journal of Medicine, vol. 347, no. 1, pp. 13-18, 2002.

[30] M. R. Venkatachalam and A. Jebanesan, "Repellent activity of Ferronia elephantum Corr. (Rutaceae) leaf extract against Aedes aegypti (L.)," Bioresource Technology, vol. 76, no. 3, pp. 287-288, 2001.

[31] R. Maheswaran and S. Ignacimuthu, "A novel herbal formulation against dengue vector mosquitoes Aedes aegypti and Aedes albopictus," Parasitology Research, vol. 110, no. 5, pp. 1801-1813, 2011.

[32] D. M. Mahmoud, M. M. Abd El-Bar, and M. H. Abdul Aziz Radi, "Combined effect of local isolate Spodoptera littoralis nucleopolyhedrosis virus and Bacillus thuringiensis on Culex pipiens L. larvae (Culicidae: Diptera)," The Journal of Basic and Applied Zoology, vol. 65, no. 1, pp. 74-78, 2012.

[33] M. J. Uriz, X. Turon, M. A. Becerro, and J. Galera, "Feeding deterrence in sponges. The role of toxicity, physical defenses, energetic contents, and life-history stage," Journal of Experimental Marine Biology and Ecology, vol. 205, no. 1-2, pp. 187-204, 1996.

[34] J. R. Pawlik, G. McFall, and S. Zea, "Does the odor from sponges of the genus Ircinia protect them from fish predators?" Journal of Chemical Ecology, vol. 28, no. 6, pp. 1103-1115, 2002.

[35] B. Haefner, "Drugs from the deep: marine natural products as drug candidates," Drug Discovery Today, vol. 8, no. 12, pp. 536544, 2003.

[36] J. Rajeevkumar and S. Xuzirong, "Biomedical compounds from marine organisms," Marine Drugs, vol. 2, pp. 123-146, 2004.

[37] A. M. S. Mayer and M. T. Hamann, "Marine pharmacology in 2001-2002: marine compounds with anthelmintic, antibacterial, anticoagulant, antidiabetic, antifungal, anti-inflammatory, antimalarial, antiplatelet, antiprotozoal, antituberculosis, and antiviral activities; Affecting the cardiovascular, immune and nervous systems and other miscellaneous mechanisms of action," Comparative Biochemistry and Physiology C, vol. 140, no. 3-4, pp. 265-286, 2005.

[38] A. M. S. Mayer, A. D. Rodríguez, R. G. S. Berlinck, and M. T. Hamann, "Marine pharmacology in 2003-4: marine compounds with anthelmintic antibacterial, anticoagulant, antifungal, anti-inflammatory, antimalarial, antiplatelet, antiprotozoal, antituberculosis, and antiviral activities; affecting the cardiovascular, immune and nervous systems, and other miscellaneous mechanisms of action," Comparative Biochemistry and Physiology C, vol. 145, no. 4, pp. 553-581, 2007.

[39] A. Kijjoa, R. Wattanadilok, W. Herz, N. Campos, M. S. J. Nascimento, and M. Pinto, "Anticancer activity evaluation of kuanoniamines $\mathrm{A}$ and $\mathrm{C}$ isolated from the marine sponge Oceanapia sagittaria, collected from the Gulf of Thailand," Marine Drugs, vol. 5, no. 2, pp. 6-22, 2007.
[40] N. L. Thakur, R. Jain, F. Natalio, B. Hamer, A. N. Thakur, and W. E. G. Müller, "Marine molecular biology: an emerging field of biological sciences," Biotechnology Advances, vol. 26, no. 3, pp. 233-245, 2008.

[41] C. A. Volk, H. Lippert, E. Lichte, and M. Köck, "Two new haliclamines from the Arctic sponge Haliclona viscosa," European Journal of Organic Chemistry, no. 14, pp. 3154-3158, 2004.

[42] R. M. Moura, A. F. S. Queiroz, J. M. S. L. L. Fook et al., "CvL, a lectin from the marine sponge Cliona varians: isolation, characterization and its effects on pathogenic bacteria and Leishmania promastigotes," Comparative Biochemistry and Physiology A, vol. 145 , no. 4, pp. 517-523, 2006.

[43] A. D. Wright, A. McCluskey, M. J. Robertson, K. A. MacGregor, C. P. Gordon, and J. Guenther, "Anti-malarial, anti-algal, antitubercular, anti-bacterial, anti-photosynthetic, and anti-fouling activity of diterpene and diterpene isonitriles from the tropical marine sponge Cymbastela hooperi," Organic and Biomolecular Chemistry, vol. 9, no. 2, pp. 400-407, 2011.

[44] E. Galeano, O. P. Thomas, S. Robledo, D. Munoz, and A. Martinez, "Antiparasitic Bromotyrosine derivatives from the marine sponge Verongula rigida," Marine Drugs, vol. 9, no. 10, pp. 1902-1913, 2011.

[45] V. Lakshmi, S. Srivastava, S. Kumar Mishra, S. Misra, M. Verma, and S. Misra-Bhattacharya, "In vitro and in vivo antifilarial potential of marine sponge, Haliclona exigua (Kirkpatrick), against human lymphatic filarial parasite Brugia malayi," Parasitology Research, vol. 105, no. 5, pp. 1295-1301, 2009.

[46] J. Gupta, S. Misra, S. K. Mishra et al., "Antifilarial activity of marine sponge Haliclona oculata against experimental Brugia malayi infection," Experimental Parasitology, vol. 130, no. 4, pp. 449-455, 2012.

[47] A. M. S. Mayer, A. D. Rodríguez, R. G. S. Berlinck, and M. T. Hamann, "Marine pharmacology in 2005-6: Marine compounds with anthelmintic, antibacterial, anticoagulant, antifungal, anti-inflammatory, antimalarial, antiprotozoal, antituberculosis, and antiviral activities; affecting the cardiovascular, immune and nervous systems, and other miscellaneous mechanisms of action," Biochimica et Biophysica Acta, vol. 1790, no. 5, pp. 283-308, 2009.

[48] R. A. Edrada, P. Proksch, V. Wray, L. Witte, W. E. G. Müller, and R. W. M. Van Soest, "Four new bioactive manzaminetype alkaloids from the Philippine marine sponge Xestospongia ashmorica," Journal of Natural Products, vol. 59, no. 11, pp. 10561060, 1996.

[49] A. Supriyono, B. Schwarz, V. Wray et al., "Bioactive alkaloids from the tropical marine sponge Axinella carteri," Zeitschrift für Naturforschung C, vol. 50, no. 9-10, pp. 669-674, 1995.

[50] D. Rey, M.-P. Pautou, and J.-C. Meyran, "Histopathological effects of Tannic acid on the midgut epithelium of some aquatic diptera larvae," Journal of Invertebrate Pathology, vol. 73, no. 2, pp. 173-181, 1999.

[51] J.-P. David, D. Rey, M.-P. Pautou, and J.-C. Meyran, "Differential toxicity of leaf litter to dipteran larvae of mosquito developmental sites," Journal of Invertebrate Pathology, vol. 75, no. 1, pp. 9-18, 2000

[52] A. Daniel Reegan, M. Gabriel Paulraj, and S. Ignacimuthu, "Larvicidal, Ovicidal, Repellent and Histopathological effects of Orange peel (Citrus sinensis Osbeck) extracts on Anopheles stephensi Liston Mosquitoes (Diptera: Culicidae)," International Journal of Applied Biology, vol. 1, pp. 24-29, 2013. 
[53] C. Lavialle-Defaix, V. Apaire-Marchais, C. Legros et al., "Anopheles gambiae mosquito isolated neurons: a new biological model for optimizing insecticide/repellent efficacy," Journal of Neuroscience Methods, vol. 200, no. 1, pp. 68-73, 2011. 

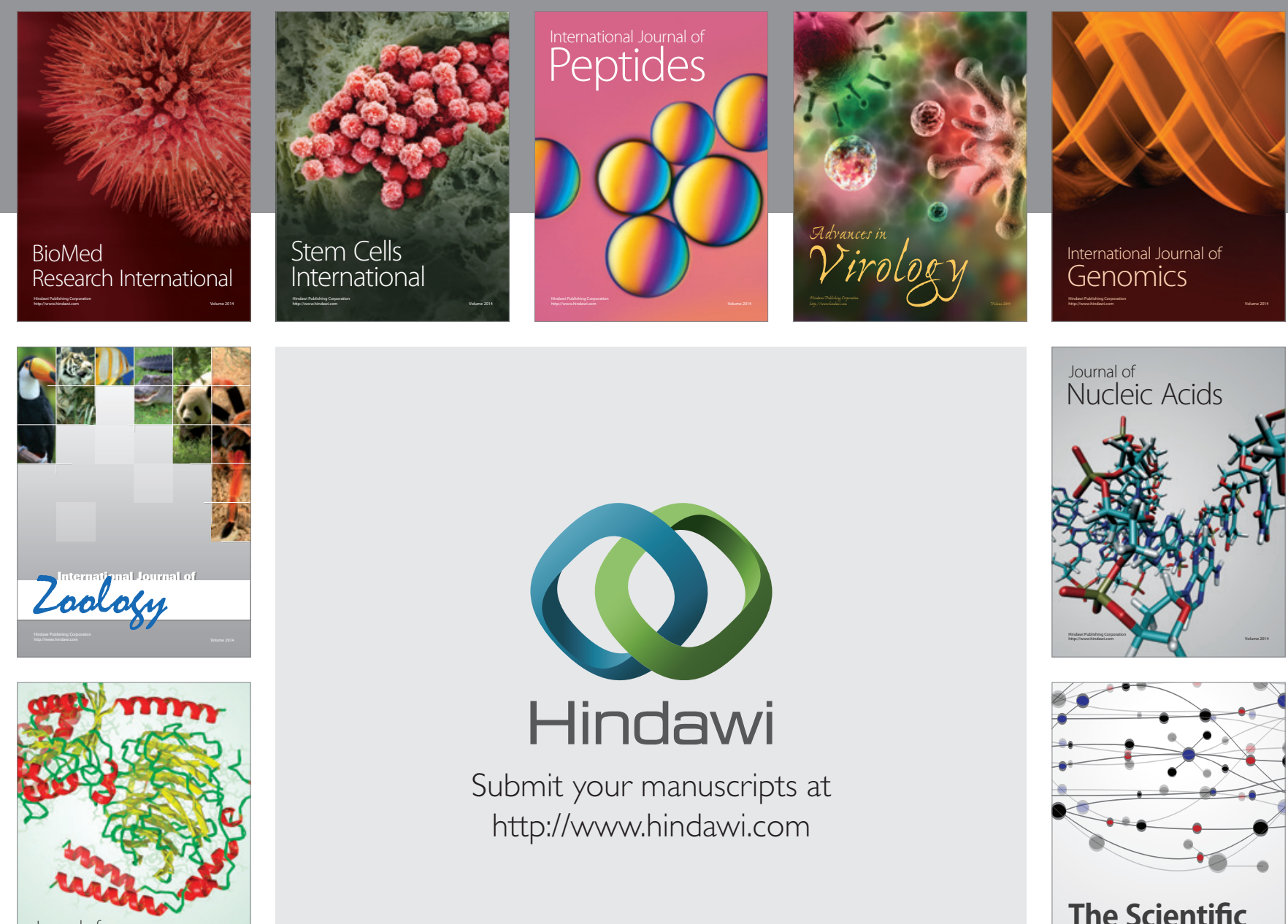

Submit your manuscripts at

http://www.hindawi.com

Journal of
Signal Transduction
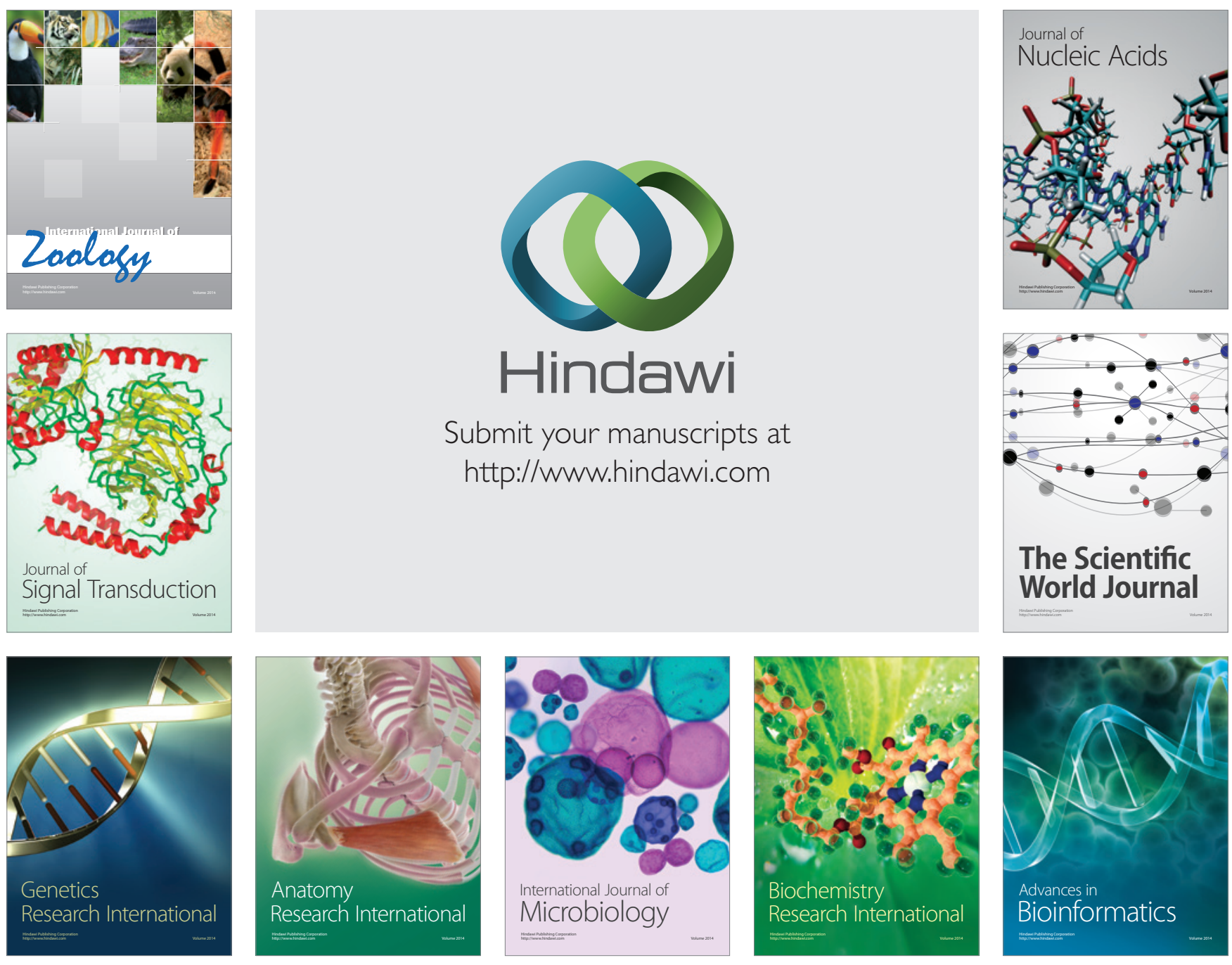

The Scientific World Journal
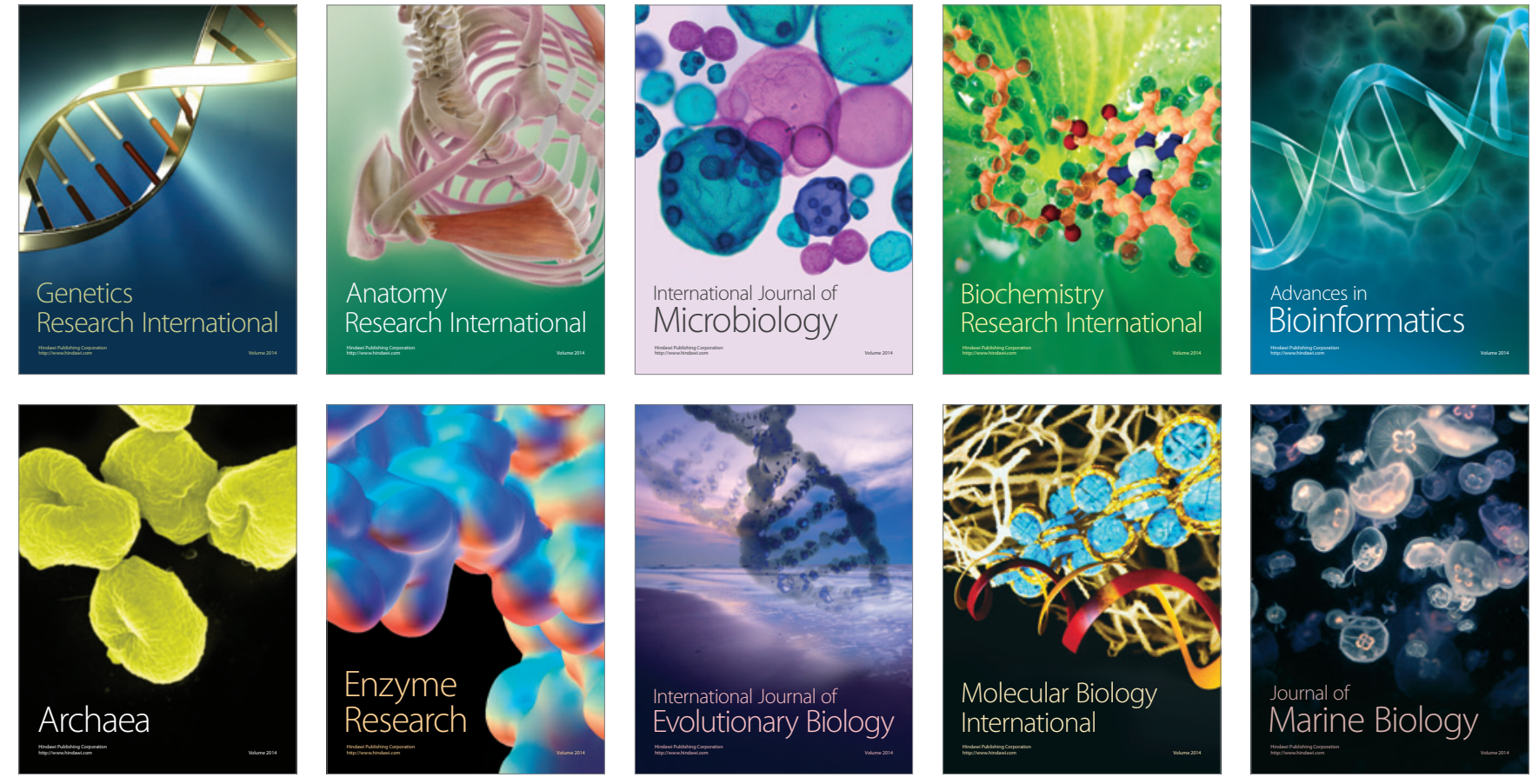